\title{
Bosnia and Herzegovina market research on the use of autonomous vehicles and drones in postal traffic
}

\author{
Amel Kosovac ${ }^{1}$, Ermin Muharemović ${ }^{1}$, Alem Čolaković ${ }^{1}$, Mirza Lakača ${ }^{2}$, Edvin Šimić ${ }^{1}$ \\ ${ }^{1}$ University of Sarajevo, Faculty of Traffic and Communications, Zmaja od Bosne 8, Sarajevo, 71000, Bosnia and Herzegovina
}

${ }^{2}$ Express One, Boce 14, Sarajevo 71000, Bosnia and Herzegovina

\begin{abstract}
New technologies primarily affect the lives of all people, their habits, needs, desires, but also significantly affect the demands placed on various business sectors. Discussions on the increasingly rapid development of technicaltechnological solutions that can be applied in the postal sector and logistics have a long history. New technologies in all areas bring a constant change in the relationship between companies and their customers, which significantly affect the quality of work and activities. In the years to come, it will be an increasing challenge for postal operators around the world, as well as for other companies, to achieve substantive communication and understanding of their customers through the application of innovative technologies. Understanding and learning about customer issues is key to offering them services that, with their precise targeting of stakeholders, quality, visibility, efficiency, and, perhaps most importantly, flexibility, will be able to meet needs that change so quickly over time. This will be possible with new technologies and innovative solutions. The paper presents a market research on the potential use of autonomous vehicles and drones in the postal sector in Bosnia and Herzegovina. The research is based on a survey questionnaire on the use of drones and autonomous vehicles in the postal sector in the segment of shipment delivery.
\end{abstract}

Keywords: postal, traffic, drones, autonomous vehicles, delivery

\section{Introduction}

The development of new technologies has contributed to the emergence of smart tools for overcoming numerous challenges in the postal sector. A relatively new concept in overcoming the challenges in goods and transport flows are innovative technologies, smart logistics, and the solutions it brings with it.

Innovative technologies can be seen as an area of integration of modern techniques and technologies to overcome the growing present challenges Reducing environmental pollution and implementing the concept of green logistics, reducing congestion in traffic, minimizing errors in performing complex business processes, increasing security, quality assurance, improving customer relations, and achieving their loyalty, are just some of the challenges facing postal and logistics systems [1]. The emergence of innovative technologies, smart logistics solutions has enabled the improvement and modernization of the postal system as we know it today. Through the introduction of modern devices, tools, and work techniques in all logistics processes, starting from the pick-up, transport, sorting, and delivery of shipments to end-users. There are numerous advantages of applying innovative technologies for both companies and their users.

With the development of the Internet of Things and the Internet of Postal Things, logistics, mail, and transport have become areas of application of comprehensive solutions for the management of goods at all times within complex delivery and transport networks [2]. Thanks to these technologies, innovative solutions are able to actively participate in processes, continuously monitor developments and inform about changes in all technological phases (transport conditions, adverse events, security threats, etc.). Innovative technologies require large initial investments.

The remaining of this paper is organized as follows. The following section describes innovative technologies, autonomous vehicles, and drones used in the phases of postal traffic technological processes, which are an integral part of market research. Section 3 provides market research on the use of autonomous vehicles and drones in Bosnia and Herzegovina. The final Section 4 contains concluding remarks. 


\section{Autonomous vehicles and drones in delivery}

The most popular and demanding innovative technologies for shipment delivery are autonomous vehicles and drones. These two technologies, the challenges and the benefits they bring, are briefly described below.

\subsection{Autonomous vehicles}

Autonomous vehicles are the technology that marks the beginning of the next revolution in the transportation of people and goods. With the rise of e-commerce as a common global practice, the number of online orders has increased significantly, as well as customer expectations for a faster delivery phase. These vehicles have become a reality due to advances in electric vehicle technology, computer vision, and machine learning. We can already see drones in the sky delivering shipments over densely populated cities or autonomous drones moving along city sidewalks and carrying hot meals for restaurants. Autonomous vehicles usually cover up a range of 10 kilometers [2].

The last kilometer of delivery is the most demanding and least predictable process in the postal system. Delivery is the basic function of the postal service, which makes it suitable for the use of autonomous vehicles. During the delivery process, delivery vehicles face other drivers, pedestrians, and cyclists, and must respect signs, signals, and intersection rules. To navigate through a dynamic environment, the autonomous vehicle must be able to respond correctly to each of the mentioned variables. In addition, the vehicle must be able to deliver the shipment to any address on its route. Such requirements include frequent stops while driving and precise coordination with the control point. Logistics companies, including postal administrations, are actively researching how to apply autonomous technology to delivery [3]-[5].

One recent example of an autonomous delivery vehicle is a small delivery robot developed by the British start-up Starship and designed to travel on pavements. According to this company, the vehicle would be used for ultra-fast CO2-neutral city deliveries at 10 to 15 times lower costs than human couriers [2].

There are innovative shipment delivery solutions in combination vans with autonomous vehicles (Figure 1). This combination reduces the negative impacts of transport on traffic congestion, safety, and the environment in large urban centers. The robots in the mentioned vehicles move on the sidewalk and do not weigh more than 20 kilograms when they are charged to full capacity [6].

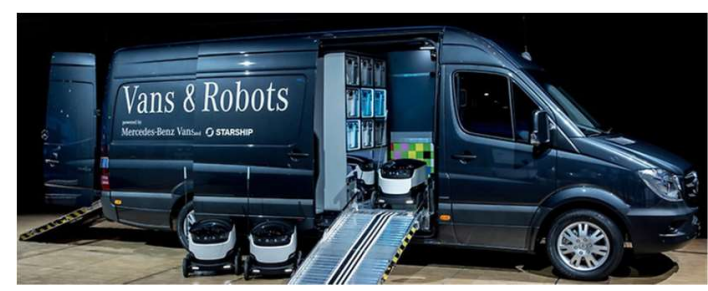

Figure 1. Truck-based autonomous robots [6]

Customers can follow the delivery process with their smartphones which are also used to unlock the goods container after the robot arrives at the destination.

Potential applications of autonomous vehicles in the postal sector are divided into two main categories: delivery to the end-user, the so-called "Last-mile delivery" and line hole transport of shipments. Within the category related to delivery, five pilot cases related to the "last mile" were identified [3]:

- an autonomous vehicle driven by the delivery man,

- autonomous self-parking vehicle,

- autonomous vehicle accompanying the delivery man,

- an autonomous vehicle that replenishes the number of shipments on delivery,

- mobile package cabinet.

Robots for delivery shipment operate on the following principle. To get from point $\mathrm{A}$ to point $\mathrm{B}$, robots need to plan a route in advance that requires some kind of map. Although many public available mapping systems already exist, such as Google Maps and Open Street Maps, they have a limitation a as they are designed primarily for car navigation with a focus on road mapping [7].

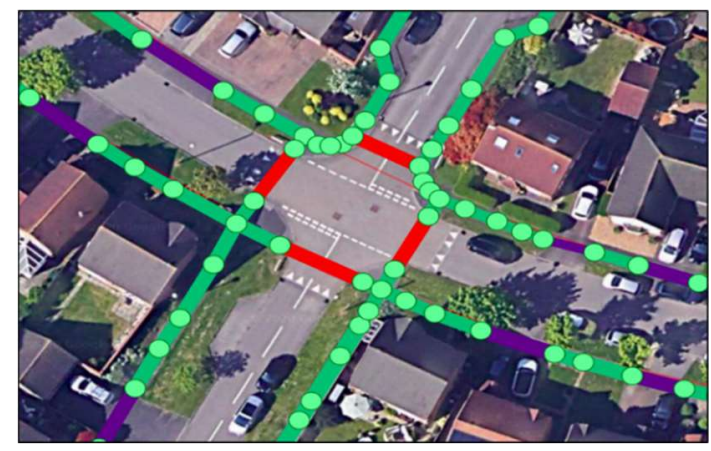

Figure 2. Preliminary map for robots [7]

Because delivery robots travel on the sidewalk, they need an accurate map that shows where it is safe to travel on the sidewalk and where they can cross the street. The first step in creating a map for delivery robots is to survey the area of interest and create a preliminary map (2D 
map), via satellite image, in the form of simple, interconnected lines, representing sidewalks (green), crossings (red) and approaches (purple), as shown in the Figure 2 [7].

The system treats this map as a graph of nodes, and can be used to generate a route from point $A$ to point $B$. The system can identify the shortest and safest route for a robot and calculate the distance and time required to drive this route. The advantage of this procedure is that everything can be done remotely, before any robots physically arrive at the scene. The last step of the mapping process, before the robots can drive completely autonomously, is an accurate calculation of where and how wide the sidewalk is. This is done by processing images, taken by the robot's camera, as well as by including a previously created 2D map based on satellite images. During this process, even more details are added to the map to precisely define the safe zones where robots can drive.

\subsection{Drones}

Drones are unmanned aerial vehicles that can be operated remotely or autonomously through computercontrolled flight plans, with built-in sensors and tracking systems. Drones are used for various purposes, but they have also found application in shipment delivery [2], [8][10].

The model of delivery by drones is several years "older" than delivery by autonomous vehicles and is usually established by rich and well-known postal companies with the aim of serving wider urban areas. Many postal companies have been testing drone deliveries lately. Unmanned aerial vehicles can be remotely controlled by pilots or can be controlled by specific sensors, systems and devices.

Drone delivery is one of the current topics in the postal industry, which is receiving a lot of attention. Many large companies such as Amazon, FedEx, DHL, and UPS are currently investigating the effective use of drones for parcel delivery [11]. For example, Figure 3 shows Amazon Prime Air drone delivery prototype.

In theory, drones could revolutionize final-stage delivery because they would make delivery by human personnel unnecessary, making the final stage more costeffective. If a flying drone is used for deliveries, its advantage is that it avoids street traffic and can reach locations without sufficient infrastructure. Flying drones also have the disadvantage that they are much less energy efficient than conventional road vehicles and usually have only a very small cargo capacity and limited range [12].

Drones consist of a large number of technologically advanced components, which enable them to operate efficiently and reliably. In addition to the physical parts, software support is very important, which is the connection between the parts, the drone and the control panel, and together with the sensors between the drone and the environment [12].

Technological processes of delivery by drones imply an efficient way of delivery of shipments and include the following activities [12]:

- pick-up packages in the center,

- going out on the runway

- takeoff,

- flying to the user's location,

- landing on the intended delivery space,

- delivery (leaving) of packages, and

- $\quad$ takeoff and return to the center.

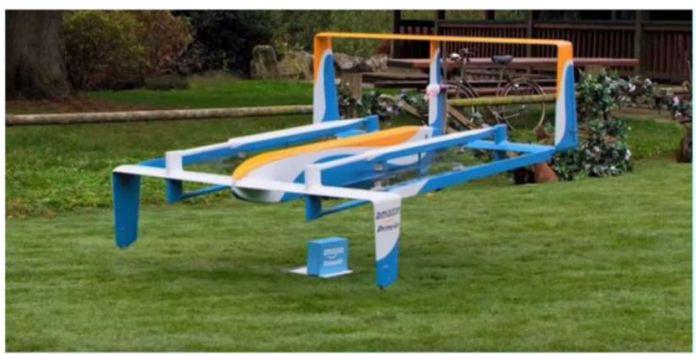

Figure 3. Amazon Prime Air drone delivery prototype [13]

The delivery of packages to drones is designed in such a way that the programmed GPS waypoints map the delivery route. The drone would take several packages for delivery and go from one delivery point to another, without the need for a pilot.

Today, some tests are being done focused on the usage combination of drones and vans [2],[11]. Figure 4 shows an example of drone delivery from truck. The van can be loaded with packages and then be transported to a specific settlement or zip code. The drones could then deliver packages from the van to customer addresses. Although this arrangement would be an additional step, the benefits of drone delivery could be increased with a lower flying range.

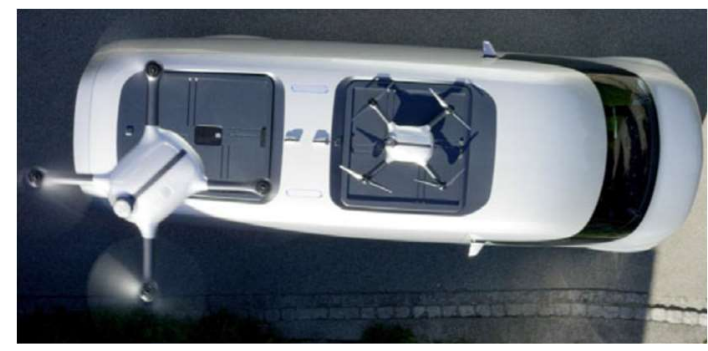

Figure 4. Drone delivery from truck [2][13] 
In these prototype models, the van has the role of a mobile warehouse for the shipments, as well as the role of a mobile launching platform for one or more drones from the roof of the van [11]. In this way, it is possible to establish the interaction of both types of vehicles.

The consignment delivery van moves from one delivery location to another, so that the driver can also perform the traditional type of delivery to the home address. At the same time, the drone delivers shipments to additional customers, one at a time, and returns to the van after each delivery. From the perspective of the analysis of the operation itself, the concept of shipments delivery by drones launched from vans opens new challenges and problems related to the creation of the route [11], [14],[2].

\section{Bosnia and Herzegovina market research on the use of autonomous vehicles and drones}

For the market research on the application of autonomous vehicles and drones, the scientific survey method was used, in which 57 respondents were included, the time period of the survey is September 2021. Respondents used the services of postal companies at least once. The authors chose the online survey method due to Covid-19 restrictions. The age structure of the respondents is from 18 to 65 years. Figure 5 shows the distribution of the age structure of the survey participants.

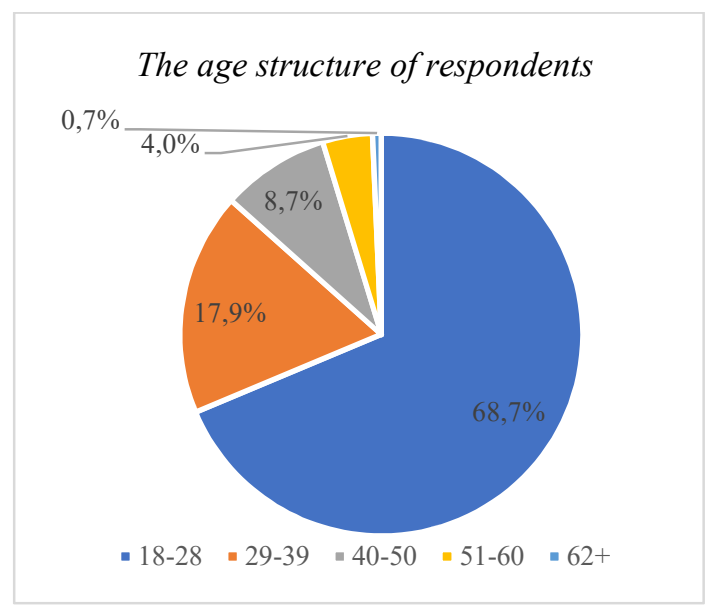

Figure 5. The age structure of respondents

The majority of respondents are in the range from 18 to 28 age with a share of $68.7 \%$. The level of education plays an important role in understanding new technologies, so the question of the level of education is included through the survey. The educational structure of the respondents is shown in Figure 6.

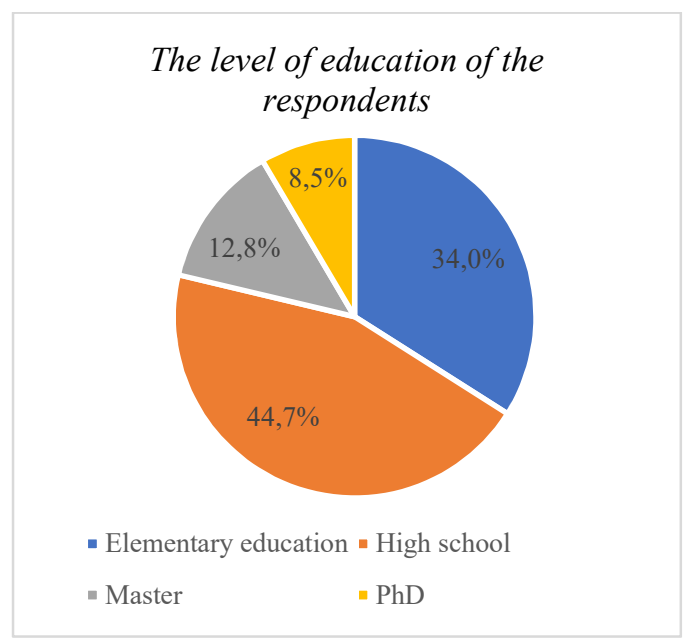

Figure 6. The level of education of the respondents

The results of the survey showed that the largest number of respondents have a high school, i.e. 26 of them. According to new ways and technologies for shipment delivery, it was necessary to ask whether they had heard of these two ways of shipment delivery. The survey question was: "Have you heard about the technology of delivering shipments with autonomous vehicles?". The results on this question are shown in Figure 7.

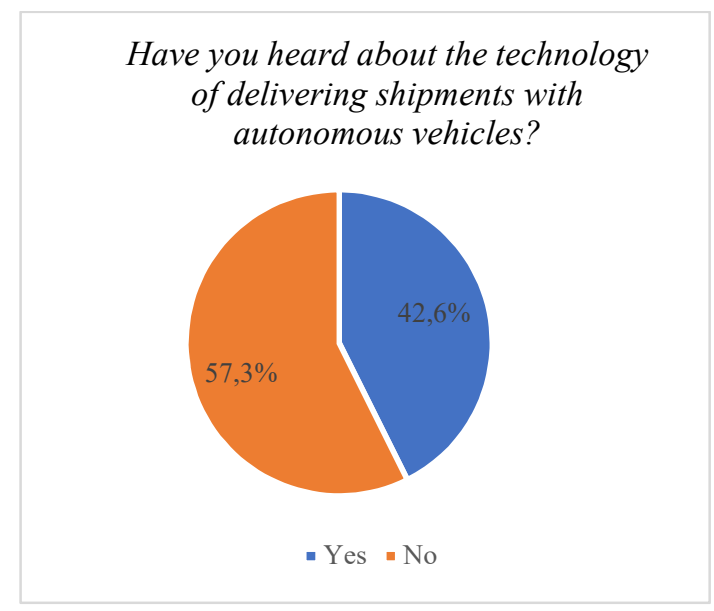

Figure 7. Question Results: Have you heard about the technology of delivering shipments with autonomous vehicles?

The results on this question show that a large number of postal services respondents are not at all familiar with the items delivery technology via autonomous vehicles. As many as $57.3 \%$ of respondents had never heard of this technology before. After this question, a short text is given about the advantages and disadvantages of the mentioned technology for delivery of shipments. After the explanation, the respondents were asked the question: "Would You use the technology of delivery shipments with autonomous vehicles (Figure 8)?“ 


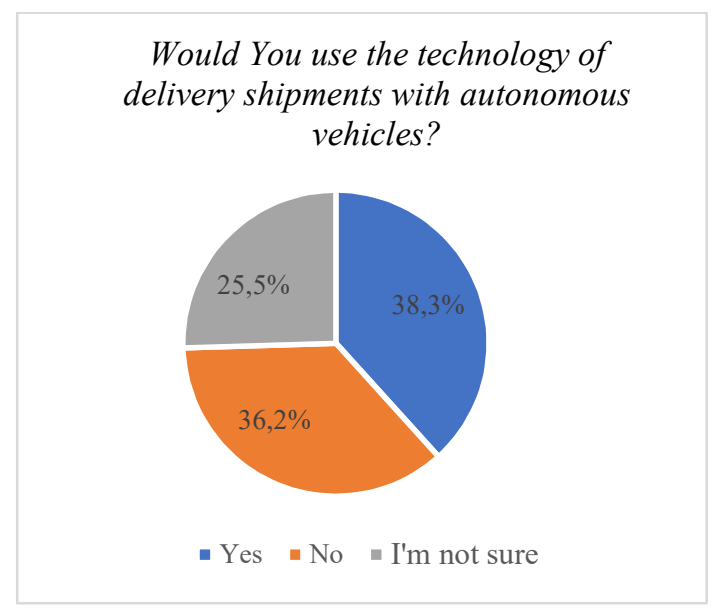

Figure 8. Question Results: Would You use the technology of delivery shipments with autonomous vehicles?

The results are quite surprising, because a very small percentage of respondents said they would use this technology, or $38.3 \%$, while $36.2 \%$ of respondents are not in favor for using this technology. As with the issues for autonomous vehicles, the same was done for drone delivery technology. The first question was related to the knowledge of the technology of delivery by drones (Figure 9).

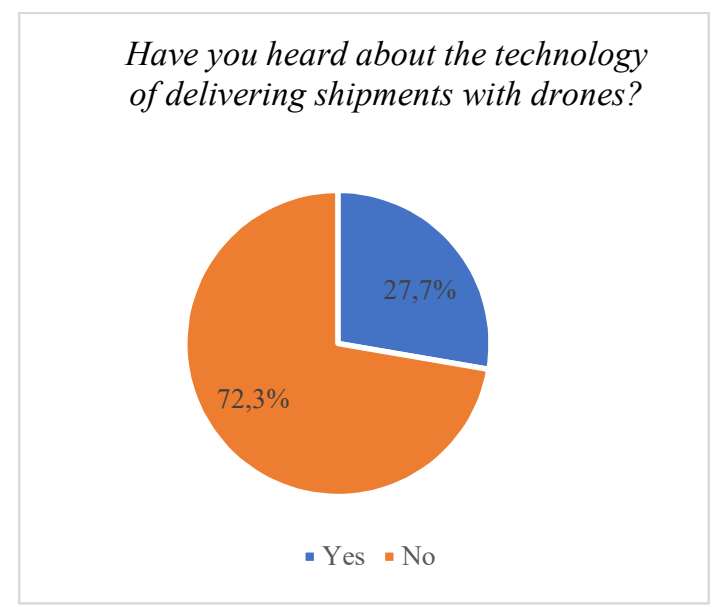

Figure 9. Question Results: Have you heard about the technology of delivering shipments with drones?

The results on this issue show that a large number of respondents of postal services in Bosnia and Herzegovina are not at all familiar with the technology of delivery by drones. The results show that $72.3 \%$ of respondents had not heard of drone delivery technology. After this question, a short text is given about the advantages and disadvantages of the mentioned technology for delivery of shipments. After the explanation, the respondents were asked the question: Would You use the technology of delivery shipments with autonomous vehicles (Figure 10)?
Would You use the technology of delivery shipments with drones?

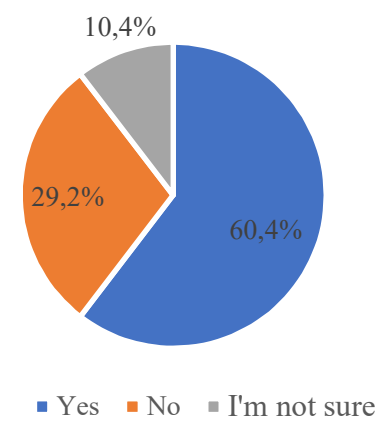

Figure 10. Question Results: Would You use the technology of delivery shipments with drones?

The results show that a large number of respondents, $60.4 \%$ of them would try to use the technology of delivery by drones, while on the other hand $29.2 \%$ of them would not use this technology.

\section{Conclusion}

The technology of delivering shipments by autonomous vehicles and drones will very soon play an important role in the operations of both postal companies and companies dealing with the last-mile-delivery process. An increasing number of postal companies are testing such systems or a combination with some other technologies, all with the aim of reducing costs, increasing productivity, reducing environmental pollution, meeting the requirements and needs of users.

Given that there is still no testing of such systems in Bosnia and Herzegovina, the authors decided to research users of postal systems, and to obtain the first results from users of such systems. The results of the survey show that a small number of respondents are familiar with these shipment delivery technologies. Also, the results of the survey show that the technology of delivery by drones is closer to the users than the technology of delivery by autonomous vehicles.

The conclusion of the survey shows that the market for delivery of shipments in Bosnia and Herzegovina is still not ready to test such systems, because a large percentage of respondents are not familiar with these technologies. For future research, the we suggest that users be surveyed on the territory of Bosnia and Herzegovina about other technologies such as PUDO and similar technology. 


\section{References}

[1] M. Savelsbergh and T. Van Woensel, "50th Anniversary Invited Article-City Logistics: Challenges and Opportunities," Transportation Science, vol. 50, no. 2, pp. 579-590, 2016.

[2] A. Kosovac, Infrastruktura poštanskog saobraćaja. Sarajevo \& Zagreb: Fakultet za saobraćaj i komunikacije, 2020.

[3] A. Čupić, M. Blagojević, and B. Stanivuković, "Mogućnost primjene autonomnih vozila u dostavi poštanskih pošiljaka," in $X X X V$ Simpozijum o novim tehnologijama $u$ poštanskom $i$ telekomunikacionom saobraćaju-PosTel 2017, 2017, p. 8.

[4] M. Blagojević, A. Čupić, and B. Stanivuković, "Primjena IoT tehnologije u poštanskom sistemu," in XXXVI Simpozijum o novim tehnologijama $u$ poštanskom i telekomunikacionom saobraćaju - PosTel 2018, 2018, p. 10.

[5] E. Muharemovic, S. Čaušević, A. Kosovac, and J. Baraković-Husić, "Cost and Performance Optimisation in the Technological Phase of Parcel Delivery - A Literature Review," Promet - Traffic\&Transportation, vol. 33, no. 1, pp. 129-139, 2021.

[6] N. Boysen, S. Schwerdfeger, and F. Weidinger, "Scheduling last-mile deliveries with truck-based autonomous robots," European Journal of Operational Research, vol. 271, no. 3, pp. 1085-1099, 2018.

[7] J. Lääne, "How Starship Delivery Robots know where they are going," Mediun, 2020. .

[8] D. N. Das, R. Sewani, J. Wang, and M. K. Tiwari, "Synchronized Truck and Drone Routing in Package Delivery Logistics," IEEE Transactions on Intelligent Transportation Systems, vol. 22, no. 9, pp. 5772-5782, Sep. 2021

[9] A. Rejeb, K. Rejeb, S. J. Simske, and H. Treiblmaier, "Drones for supply chain management and logistics: a review and research agenda," International Journal of Logistics Research and Applications, pp. 1-24, Sep. 2021.

[10] K. Dorling, J. Heinrichs, G. G. Messier, and S. Magierowski, "Vehicle Routing Problems for Drone Delivery," IEEE Transactions on Systems, Man, and Cybernetics: Systems, vol. 47, no. 1, pp. 70-85, 2017.

[11] N. Boysen, D. Briskorn, S. Fedtke, and S. Schwerdfeger, "Drone delivery from trucks: Drone scheduling for given truck routes," Networks, vol. 72, no. 4, pp. 506-527, 2018.

[12] M. Dobrodolac, D. Marković, and D. Lazarević, "Dostava pomoću dronova," in $X X X V$ Simpozijum o novim tehnologijama $u$ poštanskom $i$ telekomunikacionom saobraćaju-PosTel 2017, 2017, p. 10.

[13] J. P. Aurambout, K. Gkoumas, and B. Ciuffo, "Last mile delivery by drones: an estimation of viable market potential and access to citizens across European cities,"
European Transport Research Review, vol. 11, no. 1, 2019.

[14] G. Perboli, M. Rosano, and L. Gobbato, "Parcel delivery in urban areas : opportunities and threats for the mix of traditional and green business models," Transportation Research Part C, vol. 99, no. January, pp. 19-36, 2016. 